\title{
Five-year durability of stand-alone interspinous process decompression for lumbar spinal stenosis
}

This article was published in the following Dove Press journal:

Clinical Interventions in Aging

6 September 2017

Number of times this article has been viewed

\author{
Pierce D Nunley' \\ Vikas V Patel ${ }^{2}$ \\ Douglas G Orndorff ${ }^{3}$ \\ William F Lavelle 4 \\ Jon E Block ${ }^{5}$ \\ Fred $\mathrm{H}$ Geisler 6 \\ 'Spine Institute of Louisiana, \\ Shreveport, LA, ${ }^{2}$ The Spine Center, \\ University of Colorado Hospital, \\ Denver, CO, ${ }^{3}$ Spine Colorado, \\ Mercy Regional Hospital, Durango, \\ $\mathrm{CO},{ }^{4}$ Upstate Bone and Joint Center, \\ East Syracuse, NY, Independent \\ Consultant, San Francisco, \\ CA, 'Independent Consultant, \\ Chicago, IL, USA
}

Background: Lumbar spinal stenosis is the most common indication for spine surgery in older adults. Interspinous process decompression (IPD) using a stand-alone spacer that functions as an extension blocker offers a minimally invasive treatment option for intermittent neurogenic claudication associated with spinal stenosis.

Methods: This study evaluated the 5-year clinical outcomes for IPD (Superion ${ }^{\circledR}$ ) from a randomized controlled US Food and Drug Administration (FDA) noninferiority trial. Outcomes included Zurich Claudication Questionnaire (ZCQ) symptom severity (ss), physical function (pf), and patient satisfaction (ps) subdomains, leg and back pain visual analog scale (VAS), and Oswestry Disability Index (ODI).

Results: At 5 years, $84 \%$ of patients ( 74 of 88 ) demonstrated clinical success on at least two of three ZCQ domains. Individual ZCQ domain success rates were 75\% (66 of 88), 81\% (71 of 88 ), and 90\% (79 of 88) for ZCQss, ZCQpf, and ZCQps, respectively. Leg and back pain success rates were $80 \%$ (68 of 85 ) and $65 \%$ (55 of 85 ), respectively, and the success rate for ODI was $65 \%$ (57 of 88). Percentage improvements over baseline were $42 \%, 39 \%, 75 \%, 66 \%$, and 58\% for ZCQss, ZCQpf, leg and back pain VAS, and ODI, respectively (all $P<0.001$ ). Within-group effect sizes were classified as very large for four of five clinical outcomes (ie, $>1.0$; all $P<0.0001)$. Seventy-five percent of IPD patients were free from reoperation, revision, or supplemental fixation at their index level at 5 years.

Conclusion: After 5 years of follow-up, IPD with a stand-alone spacer provides sustained clinical benefit.

Keywords: interspinous spacer, lumbar spinal stenosis, Superion, neurogenic claudication, decompression

\section{Introduction}

Within 10 years, it is estimated that 64 million older adults will be afflicted with lumbar spinal stenosis, making it the most common indication for spine surgery in individuals older than 65 years. ${ }^{1,2}$ This expanding population of patients requires a greater range of treatment options throughout the continuum of care, particularly in the elderly who may not be appropriate candidates for open surgical procedures with the associated risks of general anesthesia. ${ }^{3}$ Interspinous process decompression (IPD) is a minimally invasive procedure that can be performed under monitored anesthesia care in an ambulatory surgery center and has been shown to provide comparable clinical performance to decompressive laminectomy for management of symptoms of spinal stenosis. ${ }^{4,5}$

Neurogenic claudication is the cardinal clinical feature of lumbar spinal stenosis, as it limits patients' walking ability and causes a major impact on their quality of life. ${ }^{6}$ Intermittent neurogenic claudication is defined as unilateral or bilateral radicular pain
Correspondence: Jon E Block 2210 Jackson Street, Ste 40I, San Francisco, CA 94I I5, USA

Tel +l 4157757947

Fax + I 4159280765

Email jb@drjonblock.com
Clinical Interventions in Aging 2017:12 |409-|4|7

1409

Dovepress f in 0

http://dx.doi.org/| 0.21 |47/CIA.SI 43503 (c) (1) (-) 2017 Nunley et al. This work is published and licensed by Dove Medical Press limited. The full terms of this license are available at https://www.dovepress.com/terms.php (c) hereby accept the Terms. Non-commercial uses of the work are permitted without any further permission from Dove Medical Press Limited, provided the work is properly attributed. For permission for commercial use of this work, please see paragraphs 4.2 and 5 of our Terms (https://www.dovepress.com/terms.php). 
during walking or standing that is relieved by sitting down or flexing the lumbar spine. ${ }^{7}$ Stenotic arthritic degeneration of the lumbar spine causes bony and ligamentous compression of neural structures axially and laterally. Indeed, constriction and impingement of nerves traversing the lateral recess and exiting the foraminal aperture are highly contributory to the most pronounced and aggravating radicular symptoms of stenosis. ${ }^{8}$

IPD employs a stand-alone spacer that functions as an extension blocker to minimize the extent of compression of neural elements, particularly in the lateral recess and foramina. ${ }^{9}$ Importantly, insertion of the spacer is performed percutaneously without surgical removal of tissue adjacent to the dura or exiting nerves. There is only one Food and Drug Administration (FDA)-approved stand-alone spacer commercially available in the USA. Herein, we provide the 5-year clinical outcomes for patients with moderate lumbar spinal stenosis treated with this IPD device.

\section{Materials and methods}

Clinical outcomes at the 5-year follow-up interval were obtained from the Superion ${ }^{\circledR}$ (VertiFlex, Inc., Carlsbad, CA, USA) treatment arm of a randomized controlled FDA noninferiority trial comparing two interspinous spacers. Methodological details of the study have been published previously. ${ }^{10,11}$ This multicenter trial evaluated the use of stand-alone IPD in the treatment of subjects aged 45 or older with moderate symptoms of intermittent neurogenic claudication, secondary to a diagnosis of moderate degenerative lumbar spinal stenosis at one or two contiguous levels from L1 to L5. Three hundred ninety-one subjects met the trial eligibility criteria and were randomized to treatment. The comparative effectiveness of these two spacers and the FDA-approved indications for use for IPD have been reported previously. ${ }^{12}$ The current 5-year analysis was restricted exclusively to the Superion arm of the trial.

This trial complied with all US regulatory requirements and was approved by the Institutional Review Board at each participating site (Table S1), and patients provided written informed consent before any study-related procedures were performed. The trial was prospectively registered at ClinicalTrials.gov (NCT00692276).

At the 5-year follow-up interval, 127 patients were free from reoperation $(n=48)$ and/or epidural steroid injection $(n=33)$, and there were 6 deaths, leaving 121 (64\%) spacer patients actively participating in the post-market period of this study. Eighty-eight of 121 active spacer patients (73\%) provided complete 5-year clinical outcome assessments by the Zurich Claudication Questionnaire (ZCQ), leg and back pain severity by visual analog scale (VAS), and the Oswestry Disability Index (ODI).

Clinical outcome data were analyzed in several ways. Success rates were calculated based on a priori definitions of the minimal clinically important difference: $\geq 0.5$-point change for ZCQ symptom severity (ss) and physical function (pf), $\leq 2.5$ points for ZCQ patient satisfaction (ps), $\geq 20 \mathrm{~mm}$ for pain VAS, and $\geq 15 \%$ points for ODI. Additionally, we computed the percentage improvement in each outcome measure at 5 years compared to preoperative values and displayed these results graphically.

The within-group effect sizes at the 5-year postoperative interval were computed and compared to baseline for each clinical outcome separately using Cohen's formula and thresholds. ${ }^{13,14}$ Effect sizes were reported in the range from 0.0 (no effect) to $>1.0$ (very large effects) with the following thresholds: 0.2 (small effect), 0.5 (medium effect), 0.8 (large effect), and $>1.0$ (very large effect).

\section{Results}

Five years after the index procedure, 74 of 88 patients $(84 \%)$ demonstrated clinical success on at least two of three ZCQ domains. The success rates for the individual ZCQ domains were $75 \%$ (66 of 88), 81\% (71 of 88), and 90\% (79 of 88) for ZCQss, ZCQpf, and ZCQps, respectively. For leg and back pain VAS, the success rates were $80 \%$ (68 of 85$)$ and $65 \%$ ( 55 of 85 ), respectively, and the rate was $65 \%$ (57 of 88 ) for ODI.

There was substantial improvement at each annual followup interval compared to baseline for the ZCQ (Figure 1), leg and back pain VAS (Figure 2), and ODI (Figure 3). Spacer patients demonstrated percentage improvements over baseline

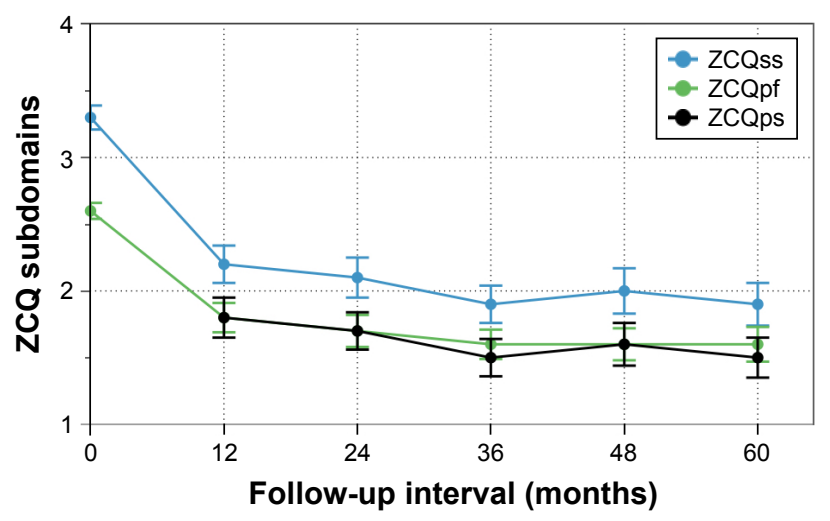

Figure I Time course of results for each subdomain of the ZCQ: ss, pf, ps. Note: Results reported as mean $(95 \% \mathrm{Cl})$.

Abbreviations: pf, physical function; ps, patient satisfaction; ss, symptom severity; ZCQ, Zurich Claudication Questionnaire. 


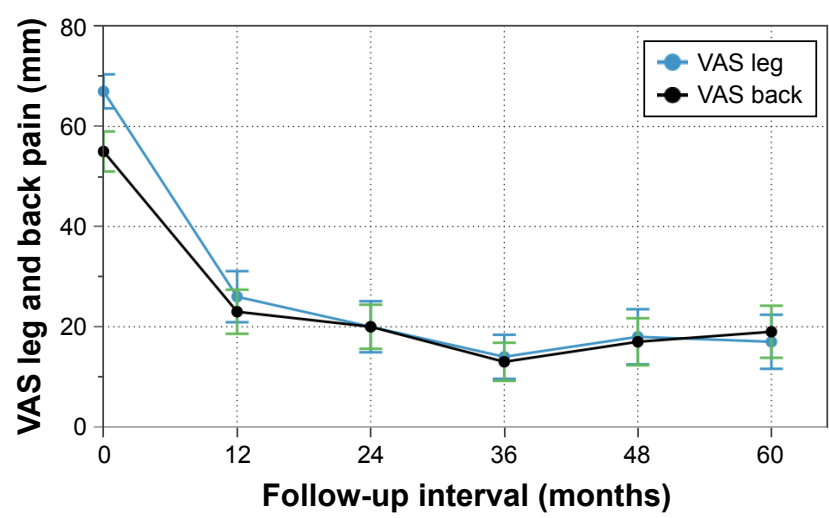

Figure 2 Time course of results for leg and back pain severity by VAS. Note: Results reported as mean $(95 \% \mathrm{Cl})$.

Abbreviation: VAS, visual analog scale.

of $42 \%, 39 \%, 75 \%, 66 \%$, and $58 \%$ for ZCQss, ZCQpf, leg and back pain VAS, and ODI, respectively (all $P<0.001$ ), as shown in Figure 4. Within-group effect sizes were classified as very large for four of five clinical outcomes (ie, $>1.0$ ): $1.35,1.40,1.32,0.97$, and 1.37 for ZCQss, ZCQpf, leg and back pain VAS, and ODI, respectively (all $P<0.0001$ ), as shown in Figure 5.

Of the 190 patients randomized to receive treatment, $142(75 \%)$ were free from reoperation, revision, or supplemental fixation at their index level at 5 years. Notably, there was a discernible trend toward decreasing risk of reoperation over time with the majority of revisions occurring during the initial 2 years of observation with annual percentage increments as follows: $27(14.2 \%), 11(5.8 \%), 3(1.6 \%), 6(3.2 \%)$, and $1(0.5 \%)$ during years $1,2,3,4$, and 5 , respectively.

\section{Discussion}

It has been estimated that $\sim 40 \%$ of patients with lumbar spinal stenosis become refractory to conservative care and will ultimately require decompression surgery within 10 years

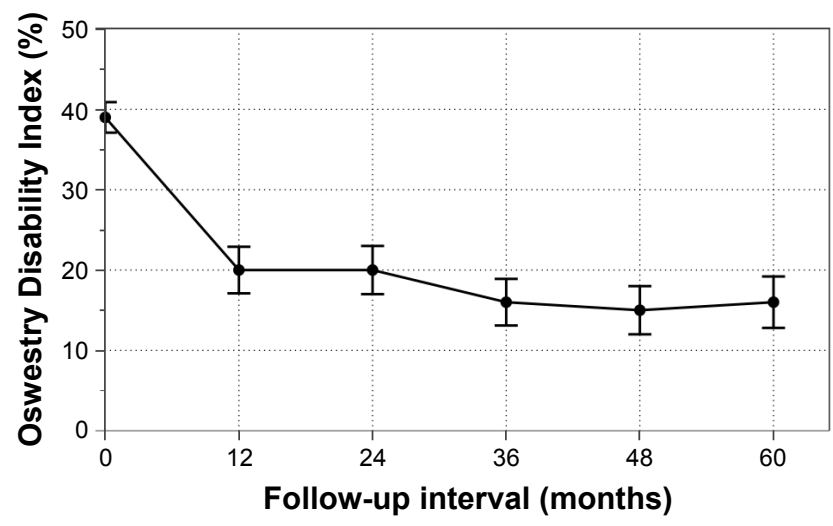

Figure 3 Time course results for the Oswestry Disability Index. Note: Results reported as mean $(95 \% \mathrm{Cl})$.

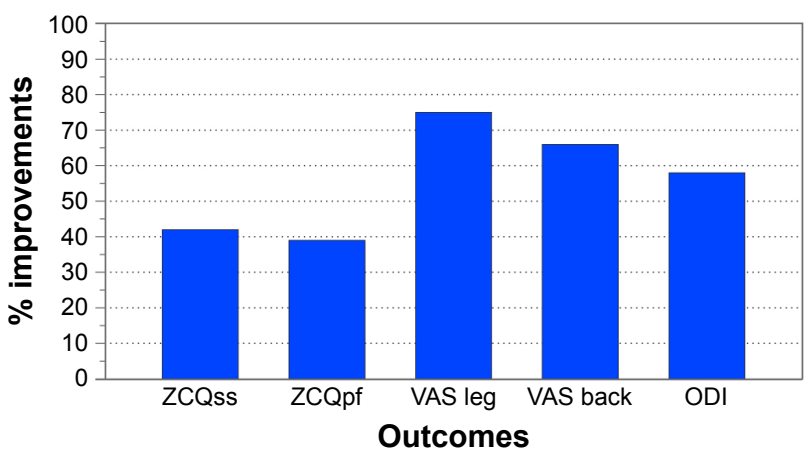

Figure 4 Percentage improvement for each outcome at 5 years compared to preoperative levels.

Note: All changes were statistically significant $(P<0.00 \mathrm{I})$.

Abbreviations: ODI, Oswestry Disability Index; pf, physical function; ss, symptom severity; VAS, visual analog scale; ZCQ, Zurich Claudication Questionnaire.

to manage persistently worsening symptoms..$^{15}$ Moreover, while laminectomy effectively decompresses the offended neural elements providing symptom relief, it can destabilize the spine, eventually leading to re-emergence of symptoms requiring reoperation with instrumented fusion. A recent randomized controlled trial reported that one-third of laminectomy patients required reoperation with fusion within 4 years. ${ }^{16}$ This rate of reoperation rate after laminectomy is comparable to a $28 \%$ rate reported from a large Washington state administrative database. ${ }^{17}$ Treatment of recalcitrant symptoms of neurogenic claudication with an interspinous spacer may significantly delay or obviate completely the need for decompressive laminectomy as well as the downstream risk of revision surgery with instrumented fusion.

This is the first report to document the long-term clinical durability of stand-alone interspinous spacer decompression for lumbar spinal stenosis through 5 years of monitored follow-up. For the $75 \%$ of spacer patients who have remained free of reoperation with an intact implant, the clinical results

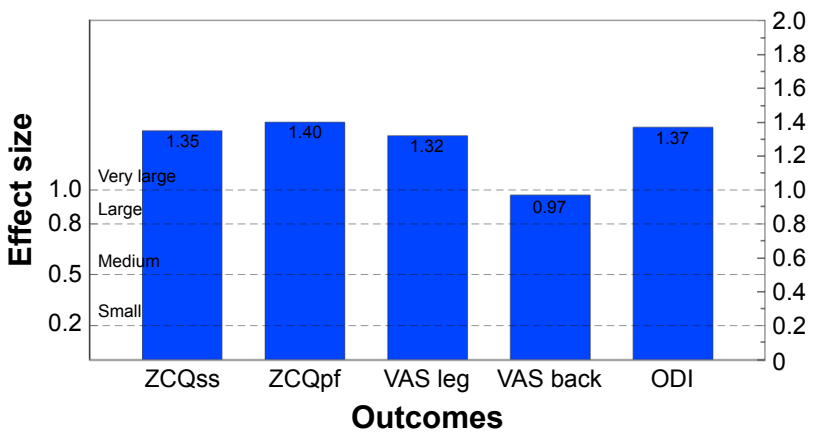

Figure 5 Within-group effect sizes for each outcome at 5 years.

Note: Effect sizes for four of five outcomes exceeded the very large threshold and all effect sizes were highly statistically significant $(P<0.000$ I).

Abbreviations: ODI, Oswestry Disability Index; pf, physical function; ss, symptom severity; VAS, visual analog scale; ZCQ, Zurich Claudication Questionnaire. 
continue to be impressive, with almost $85 \%$ of patients achieving success on at least two of three ZCQ domains. Leg pain symptom amelioration remains most notable with an average improvement of $75 \%$ at 5 years over preoperative values. This suggests that the spacer continues to offer sufficient indirect decompression of neural structures in the lateral recesses and foramina to suppress claudicant and radicular symptoms.

Thirty-eight of 48 (79\%) spacer patients underwent reoperation within the initial 2 years of postoperative observation. Of the remaining 10 reoperations, only 1 occurred during the fifth year of observation, suggesting a decreasing risk of revision surgery with time. This implies that patients who demonstrate early clinical improvement with spacer implantation will maintain that benefit over time. Clinical failures after spacer treatment can be identified early in the postoperative time course and these patients can be offered other surgical options. In contrast, reoperation rates after laminectomy tend to increase with time. ${ }^{16}$ Consequently, early clinical success may not be sustained in the long term, as outcomes eventually deteriorate due to the untoward effects of laminectomy-induced spinal instability, necessitating a complex instrumented fusion procedure to provide stabilization.

Because the IPD implantation procedure is performed in a minimally invasive fashion and causes only minor anatomic disruption, the full range of surgical options remains available if a revision becomes necessary to manage re-emergence of symptoms. Thus, with simplicity of the operative procedure, rapid patient recovery, low surgical risk of complications, and long-term clinical durability, IPD remains a viable treatment option for stenosis patients.

\section{Conclusion}

After 5 years of postoperative follow-up, IPD with a standalone spacer provides sustained clinical benefit. Its use is indicated for patients with intermittent neurogenic claudication associated with moderate lumbar spinal stenosis.

\section{Acknowledgments}

The authors wish to thank Greg Maislin for data management support and for conducting all statistical analyses. Graphical support was provided by Terry Meredith. Financial support for this work was provided by VertiFlex, Inc. (Carlsbad, CA, USA).

\section{Author contributions}

All authors contributed toward data analysis, drafting and critically revising the paper and agree to be accountable for all aspects of the work.

\section{Disclosure}

$\mathrm{JB}$ is an independent advisor to VertiFlex. The authors report no other conflicts of interest in this work.

\section{References}

1. Deyo RA. Treatment of lumbar spinal stenosis: a balancing act. Spine J. 2010;10(7):625-627.

2. Deyo RA, Mirza SK, Martin BI, Kreuter W, Goodman DC, Jarvik JG. Trends, major medical complications, and charges associated with surgery for lumbar spinal stenosis in older adults. JAMA. 2010; 303(13):1259-1265.

3. Li G, Warner M, Lang BH, Huang L, Sun LS. Epidemiology of anesthesiarelated mortality in the United States, 1999-2005. Anesthesiology. 2009;110(4):759-765.

4. Lauryssen C, Jackson RJ, Baron JM, et al. Stand-alone interspinous spacer versus decompressive laminectomy for treatment of lumbar spinal stenosis. Expert Rev Med Devices. 2015;12(6):763-769.

5. Nunley PD, Shamie AN, Blumenthal SL, Orndorff D, Block JE, Geisler FH. Interspinous process decompression: expanding treatment options for lumbar spinal stenosis. Biomed Res Int. 2016;2016:3267307.

6. Genevay S, Atlas SJ. Lumbar spinal stenosis. Best Pract Res Clin Rheumatol. 2010;24(2):253-265.

7. Katz JN, Harris MB. Clinical practice. Lumbar spinal stenosis. N Engl J Med. 2008;358(8):818-825.

8. Jenis LG, An HS. Spine update. Lumbar foraminal stenosis. Spine (Phila Pa 1976). 2000;25(3):389-394.

9. Loguidice V, Bini W, Shabat S, Miller LE, Block JE. Rationale, design and clinical performance of the superion ${ }^{\circledR}$ Interspinous Spacer: a minimally invasive implant for treatment of lumbar spinal stenosis. Expert Rev Med Devices. 2011;8(4):419-426.

10. Patel VV, Whang PG, Haley TR, et al. Superion interspinous process spacer for intermittent neurogenic claudication secondary to moderate lumbar spinal stenosis: two-year results from a randomized controlled FDA-IDE pivotal trial. Spine (Phila Pa 1976). 2015;40(5):275-282.

11. Patel VV, Whang PG, Haley TR, et al. Two-year clinical outcomes of a multicenter randomized controlled trial comparing two interspinous spacers for treatment of moderate lumbar spinal stenosis. $B M C$ Musculoskelet Disord. 2014;15:221.

12. Patel VV, Nunley PD, Whang PG, et al. Superion $\left({ }^{\circledR}\right)$ InterSpinous Spacer for treatment of moderate degenerative lumbar spinal stenosis: durable three-year results of a randomized controlled trial. J Pain Res. 2015;8:657-662.

13. Kazis LE, Anderson JJ, Meenan RF. Effect sizes for interpreting changes in health status. Med Care. 1989;27(3 Suppl):S178-S189.

14. Sullivan GM, Feinn R. Using effect size-or why the P value is not enough. J Grad Med Educ. 2012;4(3):279-282.

15. Atlas SJ, Keller RB, Wu YA, Deyo RA, Singer DE. Long-term outcomes of surgical and nonsurgical management of lumbar spinal stenosis: 8 to 10 year results from the maine lumbar spine study. Spine (Phila Pa 1976). 2005;30(8):936-943.

16. Ghogawala Z, Dziura J, Butler WE, et al. Laminectomy plus fusion versus laminectomy alone for lumbar spondylolisthesis. N Engl J Med. 2016;374(15):1424-1434.

17. Martin BI, Mirza SK, Comstock BA, Gray DT, Kreuter W, Deyo RA. Reoperation rates following lumbar spine surgery and the influence of spinal fusion procedures. Spine (Phila Pa 1976). 2007;32(3): $382-387$. 


\section{Supplementary material}

Table SI Site list of institutional review board (IRB) information

\begin{tabular}{|c|c|c|}
\hline \multicolumn{3}{|c|}{ Investigators/investigational sites } \\
\hline Site & Doctor & IRB site approved address \\
\hline \multirow[t]{2}{*}{01} & $\begin{array}{l}\text { Pierce Nunley, MD 318- } \\
629-5555 \text { (Site inactive) }\end{array}$ & $\begin{array}{l}\text { Spine Institute of Louisiana I500 Line Avenue, } \\
\text { Suite } 200 \text { Shreveport, LA 7 I I0I }\end{array}$ \\
\hline & & $\begin{array}{l}\text { *Specialist Hospital of Shreveport } 1500 \text { Line } \\
\text { Avenue, Suite } 206 \text { Shreveport, LA 7I I0 I }\end{array}$ \\
\hline \multirow[t]{4}{*}{02} & Robert Jackson, MD & Orange County Neurosurgical Associates 2396I \\
\hline & $\begin{array}{l}949-588-5800 \text { (Site } \\
\text { inactive) }\end{array}$ & $\begin{array}{l}\text { Calle de la Magdalena, Suite } 504 \text { Laguna Hills, } \\
\text { CA } 92563\end{array}$ \\
\hline & & *Saddleback Memorial Medical Center 2445I \\
\hline & & Health Center Drive Laguna Hills, CA 92563 \\
\hline \multirow[t]{3}{*}{04} & Warren Yu, MD 202- & George Washington University 2150 \\
\hline & 498-2105 (Site inactive) & Pennsylvania Avenue, NW Suite 7-416 \\
\hline & & Washington, DC 20037 \\
\hline \multirow[t]{2}{*}{08} & Vikas Patel, MD 720- & Anschutz Outpatient Pavilion 1635 North Ursula \\
\hline & 848-1980 (Site inactive) & Street MS F722, Box 6510 Aurora, CO 80045 \\
\hline
\end{tabular}

\begin{tabular}{ll} 
IRB address & IRB Chairman \\
\hline Western Institutional Review Board & Viveca Burnette \\
(WIRB) I019 39th Avenue, SE Suite I20 & $800-562-4789$
\end{tabular}

Puyallup, WA 98374-2115

*University of Colorado Hospital Anschutz

Medical Campus 12605 East 16th Avenue

Aurora, CO 80045

Lone Tree Health Center 9548 Park Meadows

Drive Lone Tree, $\mathrm{CO} 80124$

10 Vito Loguidice, MD 610- Coordinated Health Inc., 3100 Emrick Blvd., 252-1600 (Site inactive) Bethlehem, PA 18020

Office of Research Administration Van

Camp Center 2625 Pasadena Ave Long Beach, CA 90806

MHS Research Council-Mailing Address 280I Atlantic Avenue Long Beach, CA 90806

Western Institutional Review Board (WIRB) 1019 39th Avenue, SE Suite 120 Puyallup, WA 98374-2II5

Western Institutional Review Board (WIRB) 1019 39th Avenue, SE Suite 120 Puyallup, WA 98374-21 I5

Orthopedic Associates of Greater Lehigh Valley 755 Memorial Parkway Phillipsburg, NJ 08865

*Warren Hospital 185 Roseberry Street Phillipsburg, NJ 08865

II Richard Ozuna, MD 978-818-6350 (Site inactive)

13 Richard Tallarico, MD 315-464-8622 (Site inactive)

$14 \quad$ Ralph Liebelt, MD 919220-5255 (Site inactive)

Sports Medicine North One Orthopedics Drive, 2nd Floor Peabody, MA 01960

*Orthopedic Surgical Center of the North Shore One Orthopedics Drive Peabody, MA 01960 Upstate Bone and Joint Center 6620 Fly Road, Suite 200 East Syracuse, NY I3057

SUNY University of New York 750 East Adams Street, Syracuse, NY I3210-2375

*Upstate Orthopedics Ambulatory Surgery Center 6620 Fly Road, Suite 300 Syracuse, NY I 3057

Triangle Orthopedics Associates, PA 120

William Penn Plaza Durham, NC 27704

*Granville Medical Center 1010 College Street Oxford, NC 27565

North Carolina Specialty Hospital 3916 Ben

Franklin Blvd., Durham, NC 27704

Triangle Orthopedic Associates, PA 103

Professional Park Drive Oxford, NC 27565

15 Thomas Haley, DO 610- Performance Spine and Sports Physicians, PC 275-70I3 (Site inactive) 1603 East High Street, Suite C Pottstown, PA 19464

2 Lawnton Road, East Norriton, PA 1940 I
Western Institutional Review Board
(WIRB) I019 39th Avenue, SE Suite 120
Puyallup, WA 98374-2II5

Currien MacDonald 800562-4789

Warren Hospital IRB 185 Roseberry Street Phillipsburg, NJ 08865 (IRB inactive) Western Institutional Review Board (WIRB) 1019 39th Avenue, SE Suite 120 Puyallup, WA 98374-21 I5

SUNY University of New York Institutional Review Board Office 750 East Adams Street, Syracuse, NY 13210-2375

Stephen L Graziano, MD 315464-4317

Western Institutional Review Board (WIRB) 1019 39th Avenue, SE Suite 120 Puyallup, WA 98374-2115

Viveca Burnette 800-562-4789

Pottstown Memorial Medical Center IRB 1600 East High Street, Pottstown, PA 19464
James T Guille, MD 610-327-7000 Main contact below

(Continued) 
Table SI (Continued)

Investigators/investigational sites

\begin{tabular}{|c|c|c|c|c|}
\hline Site & Doctor & IRB site approved address & IRB address & IRB Chairman \\
\hline & & *Pottstown Memorial Medical I600 East High & & Courtney \\
\hline & & Street, Pottstown, PA 19464 & & Clemente IRB \\
\hline & & & & Coordinator 610- \\
\hline & & & & $327-7000$ \\
\hline \multirow[t]{3}{*}{17} & Michael Hisey, MD 940- & Texas Back Institute 2817 South Mayhill Road, & Western Institutional Review Board & Currien \\
\hline & 382-2204 (Current; Site & Suite I00 Denton, TX 76208 & (WIRB) I0I9 39th Avenue, SE Suite 120 & MacDonald 800- \\
\hline & inactive) & & Puyallup, WA 98374-2II5 & $562-4789$ \\
\hline
\end{tabular}

William Bradley, MD *Texas Back Institute, Plano 6020 West Parker

972-608-5000 (Previous) Road, Suite 200 Plano, TX 75093

Texas Back Institute, Rockwall 1005 West

Ralph Hall Parkway, Suite 227 Rockwall,

TX 75032

Texas Back Institute 400 West Arbrook

Arlington, TX 76014

Texas Back Institute, Mansfield 2800 East Broad

Street, Suite 522 Mansfield, TX 76063

Texas Health Center for Diagnostics and

Surgery 6020 West Parker Road, Plano, TX

75093

I8 Scott Kitchel, MD 54I- NeuroSpine Institute, LLC 74-B Centennial 284-0530 (Site inactive) Loop, Suite 300 Eugene, OR 9740 I

*NeuroSpine Institute, LLC 74-B Centennial Loop, Suite 100 Eugene, OR 9740I NorthWest NeuroSpine Institute 74-B Centennial Loop, Suite 200 Eugene, OR 9740I Neurosurgical Spine Institute 820I Beverly Hills Blvd., Suite 405 Los Angeles, CA 90048 310-358-2490 (Site inactive)

20 Jeffery Roh, MD 206302-0702 (Site inactive)

*Olympia Medical Center 5900 West Olympic Boulevard Los Angeles, CA 90036

ProOrtho 901 Boren Avenue, Suite 900 Seattle, WA 98104

ProOrtho 12333 NE 130th Lane, Suite 400 Kirkland, WA 98104

Evergreen Medical Center I 2040 Northeast I28th Street, Kirkland, WA 98034 *Orthopedics Intl. Ambulatory Surgery Center 600 Broadway, Suite 460 Seattle, WA 98122

23 Reginald Davis, MD 443- Greater Baltimore Neurosurgical Associates 849-4270 (Site inactive) Physicians Pavilion North 6535 N Charles Street, Suite 600 Baltimore, MD 21204 *Greater Baltimore Medical Center Institutional Review Board 670I North Charles Street Baltimore, MD 21704

Bernard Guiot, MD 720- Neurosurgery One 7780 S Broadway, Suite 350 638-7500 (Site inactive) Littleton, CO 80122

Kevin Shrock, MD 954- Shrock Orthopedic Research, LLC I4I4

764-8033 (Site inactive) Southeast 3rd Avenue Ft. Lauderdale, FL 33316

Behnam Myers, DO 3850 Sheridan Street Hollywood, FL 3302I
Western Institutional Review Board (WIRB) 1019 39th Avenue, SE Suite 120 Puyallup, WA 98374-2II5

(WIRB) 1019 39th Avenue, SE Suite 120

Viveca Burnette 800-562-4789

Western Institutional Review Board (WIRB) I0I9 39th Avenue, SE Suite 120 Puyallup, WA 98374-2115

Western Institutional Review Board (WIRB) 1019 39th Avenue, SE Suite 120 Puyallup, WA 98374-2115

Greater Baltimore Medical Center Institutional Review Board 670I North Charles Street, Baltimore, MD 21704

Porter, Littleton, and Parker Adventist Hospital Joint IRB 2525 South Downing Street, Denver, CO 80210

Western Institutional Review Board (WIRB) 1019 39th Avenue, SE Suite 120 Puyallup, WA 98374-2115
Currien MacDonald 800562-4789

Lucille Broberg 800-562-4789

Philip Levin, MD 443-849-2379

Nathaniel Hibbs, DO 303-778-2554

Paul Newton 800-562-4789 
Table SI (Continued)

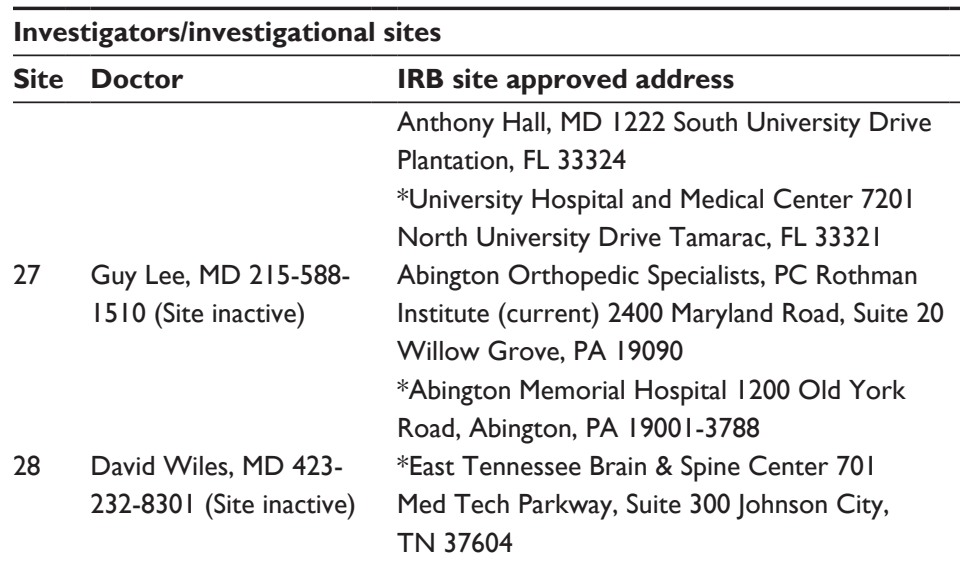

IRB address IRB Chairman

29 Edward Dohring, MD The Spine Institute of Arizona 9735 North 90th 602-953-9500 (Current; Place Scottsdale, AZ 85258

Site inactive)

Daniel Lieberman, MD Arizona Center for Neurosurgery $3300 \mathrm{~N}$. 602-256-2525 (Previous) Central Avenue, Suite 2550 Phoenix, AZ 85020

*California Spine Institute 100 I Newbury Road Newbury Park, CA 91320

Glendale Adventist Medical Center 1509 Wilson Terrace Glendale, CA 91206

*Olympia Medical Center 5900 West Olympic Blvd., Los Angeles, CA 90036

31 Harold Hess, MD 91349I-3344 (Site inactive)

Johnson County Spine 8575 West I I Oth Street,

Suite 205 Overland Park, KS 66210

*Menorah Medical Center I 19th and Nall Overland Park, KS 66204

32 Peter Whang, MD 203 785-7I32 (Site inactive)

Yale University Yale Physicians Building PO Box 20807I New Haven, CT 06520-8047

*Yale University 800 Howard Avenue New Haven, CT 06520-807I

48 Wellington Road, Milford, CT 0647।

33 Douglas Orndorff, MD 970-882-9500 (Site inactive)

34 Mark Hollmann, MD 386-734-37I0 (Site inactive)
Durango Orthopedic Associates, PC Spine

Colorado I Mercado Street, Suite 200 Durango, CO 8I30I

*Mercy Regional Medical Center 1010 Three Springs Blvd., Durango, CO 8I30 I

Florida Research Associates, PA 740 West

Plymouth Avenue Deland, FL 32720

Florida Orthopaedic Associates, PA 1053

Medical Center Drive, Suite I0I Orange City, FL 32763
Abington Memorial Hospital IRB I 200 Old

York Road, Abington, PA 1900I-3788

East Tennessee State University VA Office for the Protection of Human Research Box 70565 Johnson City, TN 37614

Western Institutional Review Board (WIRB) 1019 39th Avenue, SE Suite 120 Puyallup, WA 98374-2II5

Western Institutional Review Board (WIRB) I0I9 39th Avenue, SE Suite 120 Puyallup, WA 98374-2II5

Chris Christensen III, DO. 215-48I7467

George Youngbery, MD 423-439-6053

Viveca Burnnette 800-562-4789

Viveca Burnette 800-562-4789

James $V$ Roberts, Jr Attorney at Law Ph 25I-479-5472

Air Blvd., Suite 315 Mobile, AL 36606 25I-479-5472

Human Investigational Committee 55 College Street, New Haven, CT 065I0

Maurice Mahoney, MD, JD 230-7854688

Mercy Regional Medical Center 1010 John AK Boyd, MD Three Springs Blvd, Durango, CO 8130I

Western Institutional Review Board Viveca Burnette (WIRB) 1019 39th Avenue, SE Suite 120 800-562-4789 
Table SI (Continued)

Investigators/investigational sites

\begin{tabular}{ll}
\hline Site Doctor & IRB site approved address \\
\hline *Florida Hospital Fish Memorial 1053 Medical
\end{tabular}

Center Drive Orange City, FL 32763

35 Jeffery Baron, MD 520- Tucson Orthopaedic Institute, PC 530I East 784-60276 (Site inactive) Grant Road, Tucson, AZ 857I2

*Tucson Medical Center 530I East Grant Road Tucson, AZ 857I2

36 Harel Deutsch, MD 312- RUSH University Medical Center University 942-6644 (Site inactive) Neurosurgery 1725 West Harrison, Suite 970 Chicago, IL 60612

*RUSH University Medical Center 1653 West Congress Parkway, Chicago, IL 606I2

37 Kenneth Kopacz, MD Spine Care and Rehabilitation, Inc. 556 Eagle 973-226-2725 (Site Rock Avenue Roseland, NJ 07068 inactive)

*St Barnabas Medical Center 94 Old Short Hills Road, Livingston, NJ 07039

814-6600 (Site inactive) Metro Drive, Suite 330 Bloomington, MN 55425

*Allina Health System 800 East 28th Street Minneapolis, MN 55407

Raphael Davis, MD 631- *SUNY Stony Brook HSC 12-80 Neurosurgery 444-7925 (Site inactive) Stony Brook, NY I I 794-8I 22

40 Casey O'Donnell, DO 40I-490-7530 (Site inactive)

New England Center for Clinical Research, Inc. I68I Cranston Street, Suite C Cranston, RI 02920

*Our Lady of Fatima Hospital 200 High Service Avenue North Providence, RI 02919

$41 \quad$ Timothy Deer, MD 304- The Center for Pain Relief, Inc. 400 Court 347-6I20 (Site inactive) Street, Suite 100 Charleston, WV 2530 I

*Saint Francis Hospital 333 Laidley Street Charleston, WV 2530I

42 Robert Wailes, MD 760- Pacific Pain Medicine Consultants 3998 Vista 94I-2600 (Site inactive) Way, Suite 106 Oceanside, CA 92056

*Pacific Surgery Center 3998 Vista Way Oceanside, CA 92056

43 John Regan, MD 310 - Spine Group of Beverly Hills 8929 Wilshire 881-3730 (Site inactive) Blvd., Suite 302 Beverly Hills, CA 902I I

*Olympia Medical Center 5900 West Olympic Blvd., Los Angeles, CA 90036

IRB address IRB Chairman

Western Institutional Review Board Viveca Burnette (WIRB) I019 39th Avenue, SE Suite 120 Puyallup, WA 98374-2II 5

TMC Human Research Committee (IRB) 530I East Grant Road, Tucson, AZ 857I2

RUSH University Medical Center Research and Clinical Trials Administration 1653 West Congress Parkway Chicago, IL $60612-3833$

Department of Medical Education St Barnabas Medical Center 94 Old Short Hills Road, Livingston, NJ 07039

Schulman Associates, IRB 4445 Lake Julie Blasingim 513-

45242

Allina Hospital \& Clinics IRB 2925 Chicago

Avenue Minneapolis, MN 55440

CORIHS Stony Brook University Stony Brook, NY I I 794B Stony

Western Institutional Review Board (WIRB) 1019 39th Avenue, SE Suite 120 Puyallup, WA 98374-2I I 5

Western Institutional Review Board Lucille Broberg (WIRB) 1019 39th Avenue, SE Suite 120 Puyallup, WA 98374-2I I5 800-562-4789

Western Institutional Review Board Viveca Burnette (WIRB) 1019 39th Avenue, SE Suite 120 Puyallup, WA 98374-2II5 800-562-4789

Western Institutional Review Board Viveca Burnette (WIRB) 1019 39th Avenue, SE Suite 120 800-562-4789
Gregory J Rokosz, DO, JD 973-3225048 $76 \mid-4100$

Yvonne Rumsey 6I 2-262-4927 inactive

Prof Harold Carlson 631-6329036 Theodore Schultz 800-562-4789

800-562-4789

Carlos A Flores, MD 520-324-55I2 MD, CIP 312-9425498

Notes: Primary treatment site, *denotes a secondary clinical site. 
Clinical Interventions in Aging

\section{Publish your work in this journal}

Clinical Interventions in Aging is an international, peer-reviewed journal focusing on evidence-based reports on the value or lack thereof of treatments intended to prevent or delay the onset of maladaptive correlates of aging in human beings. This journal is indexed on PubMed Central, MedLine,

CAS, Scopus and the Elsevier Bibliographic databases. The manuscript management system is completely online and includes a very quick and fair peer-review system, which is all easy to use. Visit http://www.dovepress. $\mathrm{com} /$ testimonials.php to read real quotes from published authors.

Submit your manuscript here: http://www.dovepress.com/clinical-interventions-in-aging-journal 